Thorax (1969), 24, 527.

\title{
Chronic bronchitis in coal miners: ante-mortem/post-mortem comparisons
}

\author{
H. I. MCKENZIE, M. GLICK, A N D K. G. OUTHRED \\ From the Joint Coal Board, Sydney, Australia
}

\begin{abstract}
From bronchial measurements in 136 deceased coal miners a comparison with well-documented ante-mortem findings shows that with increasing clinical severity of chronic bronchitis there is increasing narrowing of intrapulmonary airways due to wall thickening at the expense of the lumen. With the aid of the Reid index (gland/wall ratio) and a new proposed index which more directly measures airway obstruction - the wall internal to cartilage/lumen radius ratio-both of which tend to be independent of bronchus size but change with increasing abnormality-it is possible to quantitate chronic bronchitis pathologically and to obtain satisfactory correlations with ante-mortem data. Chronic bronchitis may thereby be evaluated independently from pneumoconiosis and emphysema, thus facilitating the study of their separate relationships with cigarette smoking and with other possible aetiological factors.
\end{abstract}

As part of a long-term study of respiratory diseases in post-mortem lung specimens from coal miners we recently began measuring bronchi and calculating ratios including the Reid index (1960). The purpose of this paper is to present some of our findings, covering so far some 136 individual miners. Our objectives have been, first, to try to devise a system of severity grading of chronic bronchitis post mortem which could be satisfactorily related to the ante-mortem status; secondly, using such a system, to study the relationships of the post-mortem pathology to such ante-mortem factors as cigarette smoking and occupation, and possibly other constitutional or environmental influences. This paper covers only the first objective.

Several methods have been described for quantitating chronic bronchitis, mostly in relation to the degree of hypersecretion or mucous gland or goblet cell hyperplasia noted. The pathological signs of infection are not readily quantitated. Our own interest is mainly concerned with the obstructive phase of this disease, and with those measurable aspects of the pathology which appear to be relevant to this phase.

After examining a number of Gough sections from the lungs of miners affected by severe chronic bronchitis our interest in wall/lumen measurements was aroused by the gross wall thickening and lumen narrowing seen macroscopically, extending through most of the visible intrapulmonary tree. An attempt to quantitate this change was undertaken.

\section{CLINICAL ASPECTS}

For the individual lung/heart specimens obtained at necropsy, there are usually available the records of fully documented medical examinations (conducted at two-yearly intervals during the miners' working lives) or alternatively or as well the equally fully documented findings of workers' compensation medical boards. These examinations include a respiratory symptom questionnaire ; full routine clinical examination with emphasis on the heart and lungs ; in more recent years some tests of lung airway obstruction such as measurement of the vital capacity, peak expiratory flow rate (PEFR), forced expiratory volume in one second $\left(\mathrm{FEV}_{1}\right)$, maximum mid expiratory flow rate (MMEFR) and/or maximum breathing capacity (MBC) ; postero-anterior and frequently additional chest radiographs ; frequently also fluoroscopy and electrocardiographic examination ; and the recording in detail of the occupational history from school leaving onwards.

From long experience in periodically clinically examining miners, many of whom had chronic airways obstruction, we have come to view this condition in coal miners as a complex of pneumoconiosis (evaluated radiologically), emphysema or over-inflation (evaluated radiologically, fluoroscopically, and clinically) and chronic bronchitis with obstructed airways.

For specific diagnosis and grading of chronic bronchitis ante mortem we have required (after 
excluding the typical asthmatics) the following criteria :

1. Simple bronchitis: a history of cough with sputum on most days or mornings for at least three months of the year. This is classed as grade 1 but if infection without obstruction dominates the picture it is assigned to grade 2. However, infection without some degree of obstruction is uncommon in our miners.

2. Chronic bronchitis with airways obstruction: the above sputum history at least, plus the presence of wheezing. The latter may be present only on forced breathing or effort or after coughing. Such a patient would constitute a grade 3 chronic bronchitic on our scale.

When a subject has all the above plus a reduction in the $\mathrm{FEV}_{1}$ value per cent predicted for age and height below $70 \%$ (at which stage wheezing is usually present at rest) he would be graded 4 or 5 , depending on the degree of reduction (e.g., a grade 5 bronchitic would have $\mathrm{FEV}_{1}$ values less than $50 \%$ predicted).

Each subject was also graded for a number of individual symptoms and physical and radiological signs, many referable to emphysema rather than to bronchitis, to aid us in the clinical differentiation of these two conditions. ${ }^{1}$

These systems of classification have been in use since 1955, having, however, undergone some refinements during this period. It was necessary for us to use these simple clinical methods of grading chronic bronchitis and differentiating it from emphysema because it was not possible to refer most of our subjects to Sydney for the more intensive discriminatory physiological investigations available at the teaching centres.

Comparisons to be presented in the material which follows include only those subjects in whom these ante-mortem assessments could be based on detailed information from examinations conducted within five years of death, despite the fact that there were many additional cases in which a firm positive symptom or sign present over a longer period would have materially improved the intensity of correlation if included. Only those subjects in whom the severity of a symptom or sign, or its presence or absence, could be firmly ascertained from the records, were included.

Among the 136 subjects there were only 10 who had a clear history and diagnosis of episodic bronchial asthma responding effectively, at least for a time, to bronchodilator drugs. The postmortem findings in these subjects did not fit the

1Coding details available from the authors. Whilst appreciating the problem of observer variation in recording these details, most of these observations were recorded by one of the authors. general pattern shown hereunder and they have been excluded from the ante/post-mortem come parisons.

The inclusion of a fairly substantial proportio尺 who died from systemic hypertensive or coronary๊ heart disease or other non-pulmonary cause did not appear to have affected the bronchial pathology found in any way, though it may in some instances have impaired the correlations found with individual symptoms, for example, dyspnoeax

The age range at death of the 136 subjects was 43 to 83 years, with a skew distribution; 120 $(90 \%)$ were over 55 years. The mean was 65.4 or S.D. $8 \cdot 26$ years. All had been coal miners in New South Wales or in New South Wales plus else where - the mean duration of mining employment being $33 \cdot 3 \pm$ S.D. $11 \cdot 37$ years; $80 \%$ had had $2 \$$ years or more experience. Of the 113 whosक्ष smoking habits were recorded, $101(89 \%)$ ha been cigarette smokers.

In many of the specimens pneumoconiosis was present in varying degree. The lungs were mostl perfused by acetate formalin mixture for preparation of whole-lung sections by the Gough-Wento worth technique, and emphysema was present is most specimens. These conditions have beero studied separately. Their presence does not affecô the findings to be presented in this paper.

\section{POST-MORTEM MEASUREMENTS}

The following measurements were made wheneve possible on the lung specimens, with the aid of aneyepiece graticule in a binocular dissecting micro scope, histological slides being examined usually ap from 5 to 40 magnifications (examples of thesex measurements are shown diagrammatically in Figs 1 Aंg and $\mathrm{B})$ :

1. Thickness of mucous glands within the interna $\bar{B}$ surface of the cartilages, as recommended by LynneReid (1960)

2. Wall thickness from the epithelial basement mem brane to the internal surface of the cartilages and perpendicular thereto at the same point as the gland measurement (WIC-1). ${ }^{2}$ The Reid index (gland-walN ratio) was calculated from these two measurements

3. Where possible, total bronchial wall thicknes S $^{-}$ (TW). There was some loss of accuracy in the $\mathrm{E}_{\mathrm{W}}$ measurement owing to lack of clear definition of theo outer bronchial wall, but it was made easier in many of our specimens by the presence of dust accumulation along the outer margin.

${ }^{2}$ In the remainder of the text and graphs, where a WIC measurement is quoted in relation to gland thickness it refers to the WIC-1 as defined above; if used in relation to a lumen or walp measurement it refers to WIC-2 defined ab is necessary because, unlike Thurlbeck and some of our gland/wall measurements ade lages as permitted by Lynne Reid (Figs $1 \mathrm{~A}$ and $\mathrm{B}$ ). Had we taken them only at the centres of the cartilages the two categories ofo WIC would have been practically identical. 


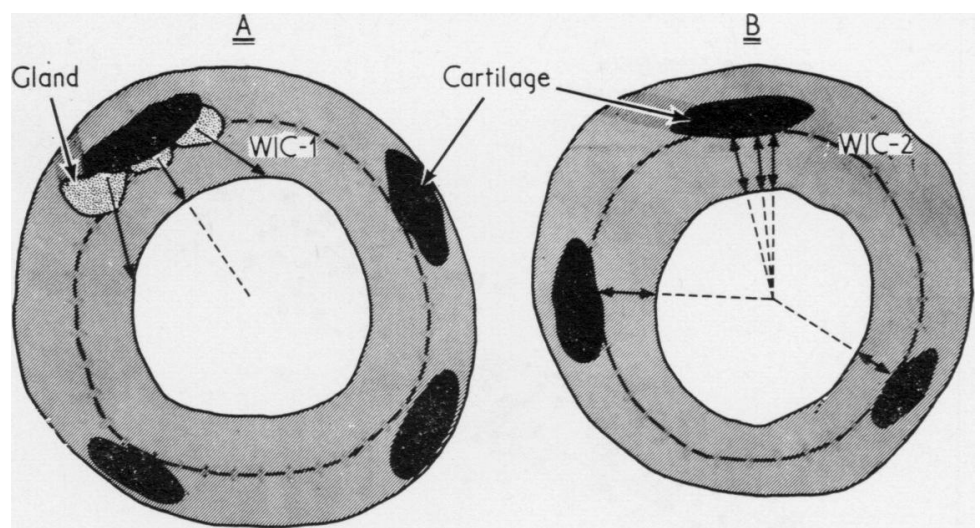

FIG. 1. Diagrammatic representation of $(A)$ central and lateral measurements of mucous gland thickness and bronchial wall thickness internal to cartilage (WIC-1), utilized for calculation of the Reid index; and $(B)$ measurements of bronchial wall internal to cartilage in line with the centre of the bronchial lumen (WIC-2), as utilized for calculation of the WIC/L ratio. These measurements were taken at or near the centres of the cartilaginous plates.

4. The radius of the bronchial lumen measured to the inner edge of the basement membrane through an assumed geometric centre, and the radius in the same line to the inner wall of the cartilage. The difference between these was a measure of the thickness of the wall internal to the cartilage (WIC-2). ${ }^{2}$ Variations in the amount of epithelial damage necessitated our standardizing on this lumen measurement to the basement membrane.

These measurements were made in a number of directions across those bronchi where the full circumference was sectioned, and the results were averaged. The number of bronchi examined per subject was determined by the material available; it varied from one to four and averaged just under two. In more recent times we have programmed our sectioning to enable at least three to four bronchi to be examined per specimen, taken from both lungs. The results were calculated to actual measurement in millimetres. Where necessary they were averaged for the particular individual for comparison with ante-mortem findings.

The following ratios were calculated to two decimal points :

Gland/Wall Internal to Cartilage (G/W) (Reid index)

Diameter of Lumen/Total Bronchus Diameter Internal to Cantilage (LD/DIC)

Wall Internal to Cartilage/Lumen Radius (WIC/L)

Total Wall/Lumen Radius (TW/L)

Wall Internal to Cartilage/Total Wall (WIC/TW)

After close study the two ratios requiring measurement of the total wall thickness (WIC/TW and TW/ L) were discarded for the reasons that $(a)$ the total wall thickness as a rule is not as accurately measureable as is the thickness to the inner wall of the

see footnote on previous page. cartilage, and $(b)$ in our hands these ratios did not prove as discriminatory nor correlate as well with individual symptoms and signs or with bronchitis grade as did the $G / W$ and WIC/L ratios. The LD/ DIC was likewise too insensitive adequately to separate grades of severity of disease and was also discarded.

The following material presents our findings in relation to absolute values of certain measurements and to the two remaining ratios, the Reid index and the WIC/L ratio.

Some 241 bronchi from 136 individuals were measured. The averaged findings in absolute values and in either ratio were compared with the size of bronchi and the ratios also with the ante-mortem findings. Almost all the bronchi measured were intrapulmonary; the mean external diameter was $5.42 \mathrm{~mm}$. ( \pm S.D. 1.94) and the mean lumen diameter 2.44 mm. ( \pm S.D. $0 \cdot 78)$.

ABSOlute values In Fig. 2 the total wall thickness of each bronchus in millimetres has been plotted against its approximate overall size (calculated by summing lumen radius and total wall thickness and doubling). It will be seen that there is a linear relationship between them, with a high order of correlation ; in other words, the total wall thickness has a constant ratio to bronchus size within the limits of the latter studied, namely $2 \mathrm{~mm}$. to $10 \mathrm{~mm}$. overall diameter. This covered a range from small through subsegmental and segmental to lobar bronchi.

Figure 2 includes both normal and abnormal bronchi ; nevertheless, a high degree of correlation is still present, despite the fact that the wall thick- 


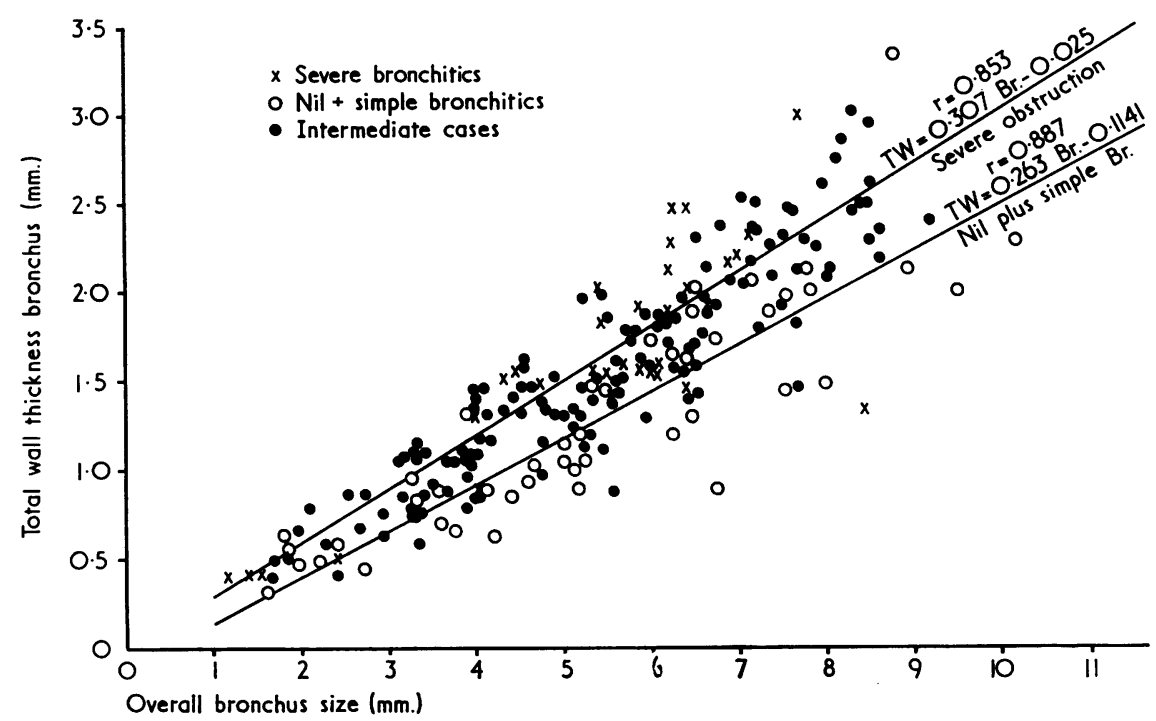

FIG. 2. The ratio of bronchial wall thickness to bronchus size (and thus to lumen) remains constant with varying size of intrapulmonary bronchus but increases in obstructive bronchial disease. This increase likewise appears to be largely independent of size of bronchus. (Measurements from subjects who had severe bronchial airway obstruction ante mortem are compared with those with nil obstruction and with those with intermediate degrees of obstruction.)

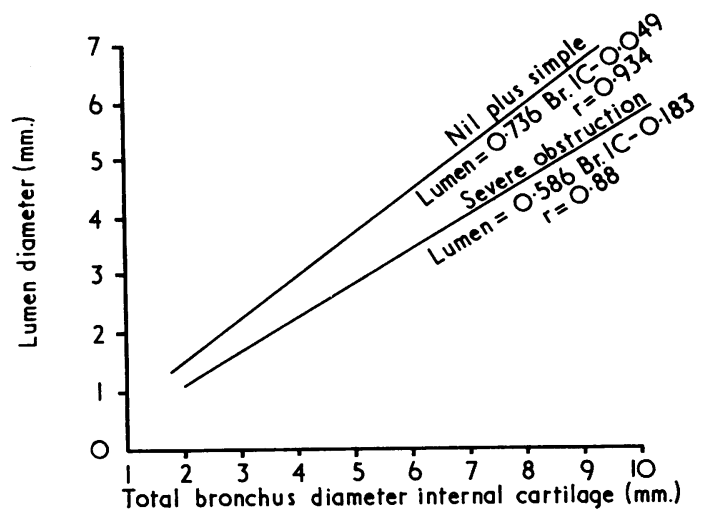

FIG. 3. Change in ratio of lumen diameter to diameter of bronchus internal to cartilaginous plates in severe obstructive 'bronchial' disease as compared with 'nil obstructives' (subjects who had no chronic bronchitis or were chronic expectorators without clinical airways obstruction).

ness increases in chronic bronchitis. Two regression lines have been superimposed on this figure. One shows the situation with respect to those subjects who had no symptoms nor signs of obstructive bronchitis when last examined ('nil' plus 'simple' chronic bronchitis) and the other, those who had the most severe grade of obstructive bronchitis (grade 5). The shift in the severe obstructives towards a thicker bronchial wall for a given size of bronchus is evident. There were若 insufficient 'nil' cases to compare these separately no doubt had we been able to do so the shifto would have been somewhat greater.

From visual inspection the thickening takes place largely, if not wholly, at the expense of the lumen. To obtain absolute proof of this would require sharp standardization of bronchus level as between normals and abnormals - something very.x difficult to achieve. Inasmuch as we found no shift in the range of bronchus sizes between the normal and abnormal extremes, our findings pro을 vide confirmation of this concept of internal wall thickening and resultant relative lumen narrow- -5 ing. Figure 3 shows that for a given size of bronchus we found lumen narrowing in abnormals as compared with non-obstructives-again with no corresponding systematic shift in the limits of overall bronchus size.

In our experience, these changes, though wide- $-\omega$ spread, are not entirely uniform throughout the bronchial tree in a particular individual. In ad vanced cases they tend to be more generalized.

Figure 4 suggests that the cartilaginous frame-? work neither expands nor contracts in bronchitis $\frac{0}{0}$ with airways obstruction.

Table I presents some of the mean absolute? values and their standard deviations obtained in $\mathbb{Q}$ the derivation of the regression lines shown in Figures 2 to 4 . 


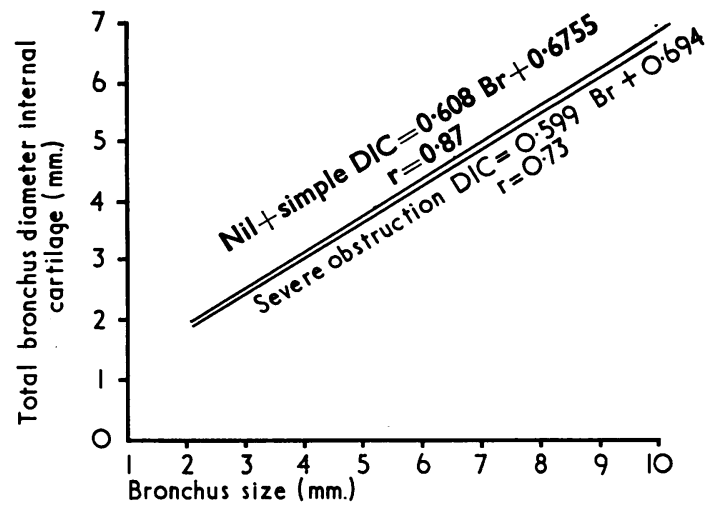

FIG. 4. Lack of change with ante-mortem severity of bronchial obstruction in the diameter of intrapulmonary bronchi as measured from the inner surfaces of the cartilaginous plates. This diameter bears a constant relationship to total bronchus diameter and is more accurately measurable in the absence of pneumoconiosis.

T A B L E I

ABSOLUTE VALUES OF BRONCHIAL MEASUREMENTS IN NORMAL OR NEAR-NORMAL SUBJECTS AND IN CHRONIC BRONCHITICS WITH SEVERE OBSTRUCTION

\begin{tabular}{c|c|c|c|c}
\hline & $\begin{array}{c}\text { Nil } \\
\text { plus } \\
\text { Simple } \\
\text { Chronic } \\
\text { Bronchitis }\end{array}$ & $\begin{array}{c}\text { No. of } \\
\text { Bronchi } \\
\text { Measured }\end{array}$ & $\begin{array}{c}\text { Chronic } \\
\text { Bronchitis } \\
\text { with } \\
\text { Severe } \\
\text { Obstruction }\end{array}$ & $\begin{array}{c}\text { No. of } \\
\text { Bronchi } \\
\text { Measured }\end{array}$ \\
\hline $\begin{array}{c}\text { Gland thickness } \\
\text { (mm.) } \\
\text { Bronchus overail } \\
\text { diameter (mm.) }\end{array}$ & $0.24 \pm 0.12$ & 45 & $0.54 \pm 0.27$ & 25 \\
\hline $\begin{array}{c}\text { Lumen radius } \\
\text { (mm.) }\end{array}$ & $1.41 \pm 0.17$ & 45 & $5.70 \pm 1.73$ & 25 \\
$\begin{array}{c}\text { Wall internal to } \\
\text { cartilage (mm.) } \\
\text { (WIC-2) }\end{array}$ & $0.52 \pm 0.26$ & 50 & $0.95 \pm 0.39$ & 32 \\
\hline $\begin{array}{c}\text { Wall internal to } \\
\text { cartilage (mm.) } \\
\text { (WIC-2) }\end{array}$ & $0.52 \pm 0.26$ & 50 & $0.95 \pm 0.39$ & 32 \\
$\begin{array}{c}\text { Total wall thick- } \\
\text { ness (mm.) }\end{array}$ & $1.33 \pm 0.64$ & 50 & $1.68 \pm 0.68$ & 32 \\
\hline
\end{tabular}

The following points are of interest:

1. The mean gland thickness in the severe bronchitis group is slightly more than double the thickness in the nil plus simple bronchitis group, this increase occurring despite the fact that the mean overall bronchus diameter is almost the same in both groups. The gland thickness increases by an average of $0.30 \mathrm{~mm}$.

2. The lumen radius diminishes by $0.31 \mathrm{~mm}$. in the chronic bronchitics with severe obstruction. Also the total wall enlarges by $0.35 \mathrm{~mm}$. in the same group. It will be noted that the mean WIC-2 increases by a larger amount $-0.43 \mathrm{~mm}$. This is explained by the fact that not all such measure- ments were made at the centres of the cartilaginous plates (see Fig. 1B).

3. The amount of shrinkage of the lumen of a bronchitic at our severest grade of obstruction (grade 5) is sufficient to reduce its cross-sectional area to $50 \%$ of its normal value. This may well be considered relevant to the degree of obstruction present clinically in severe airways obstruction, as measured by such tests as the $\mathrm{MBC}, \mathrm{FEV}_{1}$, MMEFR, and PEFR.

RATIOS The absolute values vary with the size of the bronchus and it was because of this that, like Reid, Thurlbeck, and others, we decided to use ratios which are relatively independent of bronchus size over a wide range yet change sufficiently with the degree of chronic bronchitis to permit their use in severity gradings suitable for epidemiological work. This obviates the need for precise specification of a location in the bronchial tree at which sections must be cut. We were looking for a ratio which might be used, together with the Reid index, for assessment of chronic bronchitis in pathological specimens but which might permit better definition of the obstructive stages than the Reid index. The WIC/L ratio appeared prima facie to be likely to meet our requirements.

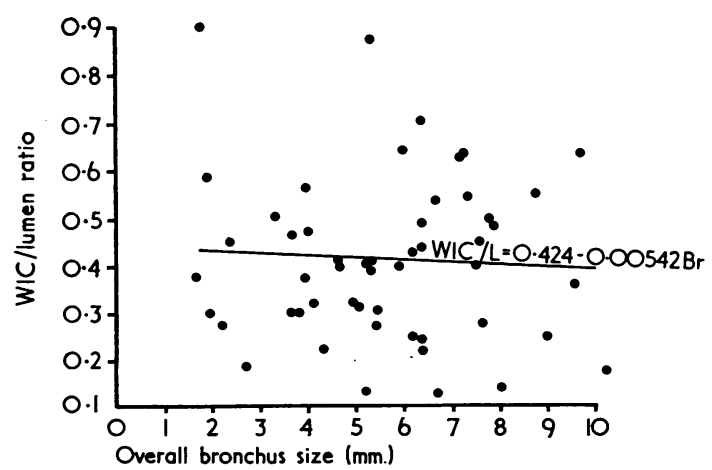

FIG. 5. Constancy of wall thickness internal to cartilage/ lumen radius ratio with varying bronchus size in 'nonobstructive' subjects. The lumen radius is normally about two and $a$ half times the intracartilaginous wall thickness.

In studying ratios to begin with we plotted each ratio in normal or near normal bronchi (nonobstructed subjects) against the overall size of the bronchus. The results for the WIC/L ratio are given in Figure 5. Only bronchi from subjects who had no more than simple chronic bronchitis when last examined were included in these diagrams.

Figure 5 confirms that in the normal or near normal bronchus this ratio, like the Reid index, 


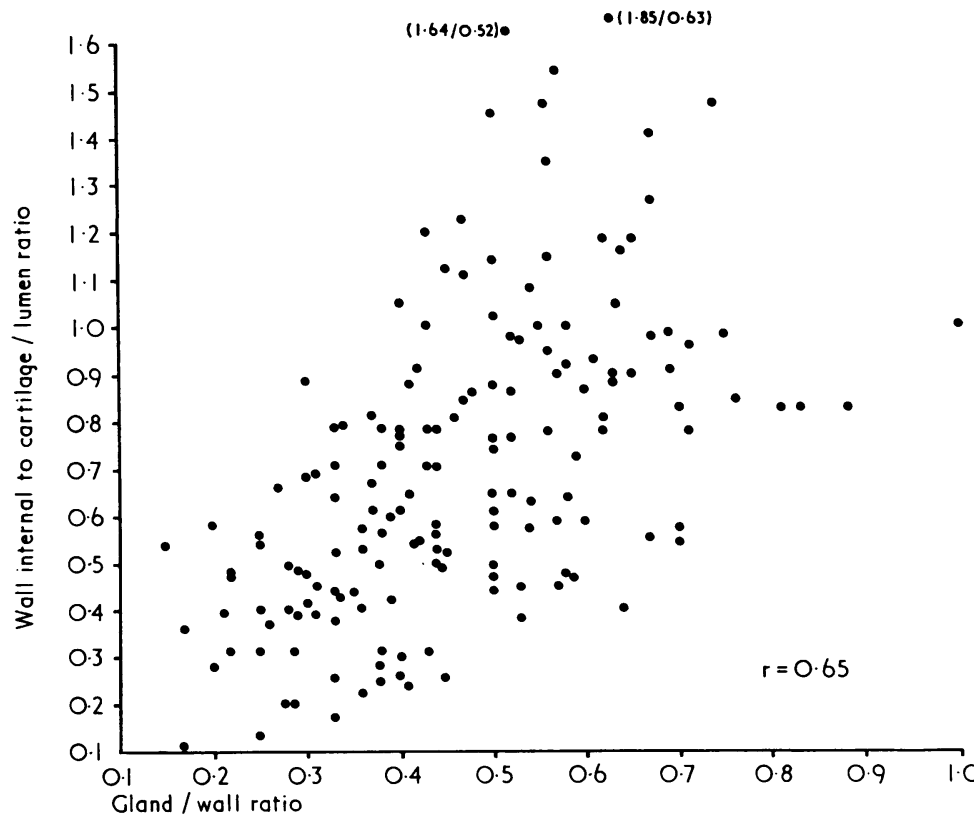

FIG. 6. Correlation between WIC/志 ratio and Reid index $(r=0 \cdot 65)$

T A B L E II

CORRELATION WITH ANTE-MORTEM DISEASE GRADINGS

\begin{tabular}{|c|c|c|c|c|c|}
\hline & $\begin{array}{l}\text { Nil Chronic } \\
\text { Bronchitis }^{1}\end{array}$ & $\begin{array}{c}\text { Simple Chronic } \\
\text { Bronchitis }^{1}\end{array}$ & $\begin{array}{l}\text { Chronic Bronchitis } \\
\text { Mildly Obstructive }\end{array}$ & $\begin{array}{c}\text { Chronic } \\
\text { Bronchitis } \\
\text { Moderately } \\
\text { Obstructive }^{1}\end{array}$ & $\begin{array}{l}\text { Chronic } \\
\text { Bronchitis } \\
\text { Severely } \\
\text { Obstructive }\end{array}$ \\
\hline 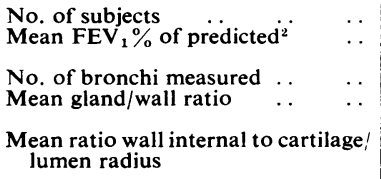 & $\begin{array}{c}5 \\
104 \% \\
(3) \\
6 \\
0.28 \pm 0.063 \\
(0.024) \\
0 \cdot 36 \pm 0 \cdot 16 \\
(0.0653)\end{array}$ & $\begin{array}{l}27 \\
84 \% \\
(19) \\
44 \\
0 \cdot 34 \pm 0 \cdot 10 \\
(0 \cdot 016) \\
0 \cdot 40 \pm 0 \cdot 18 \\
(0 \cdot 027)\end{array}$ & $\begin{array}{c}17 \\
66 \% \\
(14) \\
36 \\
0.41 \pm 0.09 \\
(0 \cdot 015) \\
0.63 \pm 0.12 \\
(0.020)\end{array}$ & $\begin{array}{l}15 \\
55 \% \\
(13) \\
29 \\
0 \cdot 51 \pm 0 \cdot 11 \\
(0 \cdot 02043) \\
0 \cdot 88 \pm 0 \cdot 21 \\
(0 \cdot 0390)\end{array}$ & $\begin{array}{l}13 \\
39 \% \\
(13) \\
28 \\
0 \cdot 55 \pm 0 \cdot 09 \\
(0 \cdot 0170) \\
1 \cdot 04 \pm 0 \cdot 26 \\
(0.0491)\end{array}$ \\
\hline
\end{tabular}

${ }^{1}$ With or without emphysema and/or pneumoconiosis (asthmatics excluded)

${ }^{2}$ No. of cases in parentheses indicate those in which respiratory function test results are on record.

N.B. (1) Mean \pm standard deviation in each instance.

(2) S.E. mean shown in parentheses.

tends to remain constant or nearly so with the size of the bronchus, though there is considerable variability in individual bronchi.

In Fig. 6 the WIC/L ratio is plotted against the $\mathrm{G} / \mathrm{W}$ ratio. Each point represents the mean for an individual, and all persons normal and abnormal in terms of bronchitis are included. In this diagram a relationship is demonstrated which appears to be linear, though with fairly wide and rather irregular spread of individual points. A fair degree of correlation is demonstrated $(r=0.65)$. In general, our findings with the Reid index for various grades of disease were identical with those published on various occasions by Lynne Reid, and the distribution of this index was similar to that given by Thurlbeck and Angus (1964).
Considering the overall picture shown in Fig 2 to 6 , the indications are, first, that bronchi witks in the range of approximately $2 \mathrm{~mm}$. to $10 \mathrm{~mm}$. overall size can be satisfactorily used for assessing chronic bronchitis, and, secondly, that the size is not important within this range and using ratios rather than absolute measurements. We do nof recommend using bronchi smaller than about $2.5 \mathrm{~mm}$. for two reasons; first that we find the discrimination between obstructives and nor\$ obstructives using any of the ratios is rather less satisfactory in these very small bronchi, and secondly that in such bronchi it is often impossible to find a satisfactory mucous gland for measure ment. Above about $7.5 \mathrm{~mm}$. size, the variabilit and overlap between normals and abnorma 


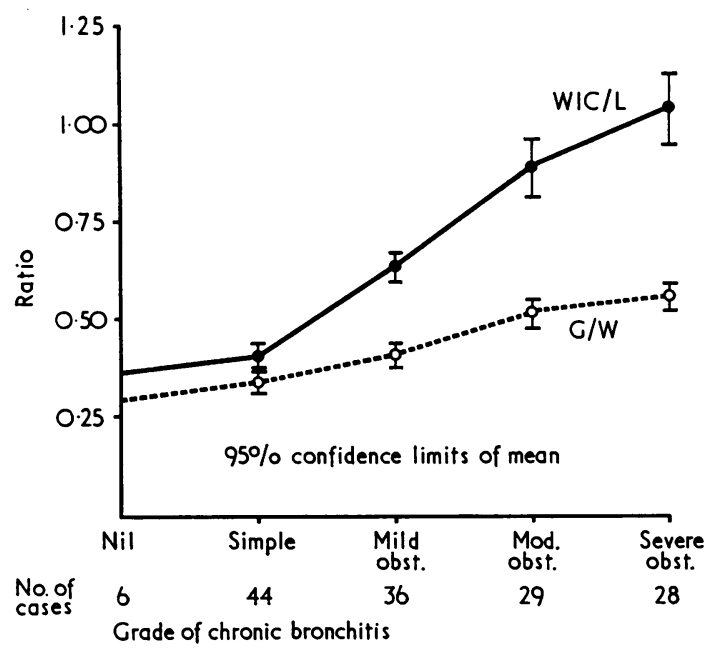

FIG. 7. Mean values and the $95 \%$ confidence limits of the $W I C / L$ ratio and the Reid index for each of five grades of ante-mortem severity of chronic bronchitis-from 'nil bronchitis' to 'severe obstructive bronchial disease'.

T A B L E I I I

SYMPTOMS AND SIGNS (WITHIN FIVE YEARS OF DEATH) $v$. BRONCHITIS RATIOS. CORRELATION COEFFICIENTS

\begin{tabular}{|c|c|c|c|c|c|}
\hline \multirow{2}{*}{\multicolumn{2}{|c|}{ Ratio }} & \multirow{2}{*}{$\frac{G}{\mathbf{W}}$} & \multirow{2}{*}{$\frac{\text { WIC }}{\mathrm{L}}$} & \multicolumn{2}{|c|}{ No. of Subjects } \\
\hline & & & & $\frac{\mathbf{G}}{\mathbf{W}}$ & $\frac{\text { WIC }}{\mathrm{L}}$ \\
\hline $\mathrm{FEV}_{1} \%$ predicted $\ldots$ & .. & $0 \cdot 743$ & 0.745 & 54 & 52 \\
\hline $\begin{array}{l}\text { Sputum history }^{1} \\
\text { Dyspnoea }^{\mathbf{1}} \quad \ldots \\
\text { History of wheezing }\end{array}$ & $\begin{array}{l}\cdots \\
\cdots\end{array}$ & $\begin{array}{l}0 \cdot 450 \\
0 \cdot 298 \\
0 \cdot 491\end{array}$ & $\begin{array}{l}0.549 \\
0 \cdot 483 \\
0 \cdot 573\end{array}$ & $\begin{array}{l}66 \\
73 \\
67\end{array}$ & $\begin{array}{l}61 \\
66 \\
60\end{array}$ \\
\hline $\begin{array}{l}\text { Wheezes } \\
\text { Observed breathlessness } \\
\text { Prolonged expiration }\end{array}$ & $\begin{array}{l}\ldots \\
\cdots \\
\cdots\end{array}$ & $\begin{array}{l}0.592 \\
0 \cdot 412 \\
0 \cdot 463\end{array}$ & $\begin{array}{l}0.638 \\
0.434 \\
0.569\end{array}$ & $\begin{array}{l}74 \\
63 \\
64\end{array}$ & $\begin{array}{l}66 \\
58 \\
59\end{array}$ \\
\hline $\begin{array}{l}\text { Percussion hyperresonance } \\
\text { Distant breath sounds } \\
\text { Distant heart sounds }\end{array}$ & $\begin{array}{l}\cdots \\
\cdots \\
\cdots\end{array}$ & $\begin{array}{l}0 \cdot 377 \\
0 \cdot 111 \\
0 \cdot 249\end{array}$ & $\begin{array}{l}0 \cdot 355 \\
0 \cdot 395 \\
0 \cdot 316\end{array}$ & $\begin{array}{l}68 \\
69 \\
71\end{array}$ & $\begin{array}{l}62 \\
63 \\
74\end{array}$ \\
\hline $\begin{array}{l}\text { Radiographic findings } \\
\text { Diminished lung marking } \\
\text { Low flat diaphragm } \\
\text { Small central heart shado } \\
\text { Large retro-sternal windo } \\
\text { Enlarged A.P. thoracic } \\
\text { diamet }\end{array}$ & & $\begin{array}{l}0 \cdot 244 \\
0 \cdot 335 \\
0 \cdot 146 \\
0 \cdot 395\end{array}$ & $\begin{array}{l}0 \cdot 285 \\
0 \cdot 471 \\
0 \cdot 268 \\
0 \cdot 324\end{array}$ & $\begin{array}{l}66 \\
68 \\
65 \\
48\end{array}$ & $\begin{array}{l}60 \\
61 \\
69 \\
42\end{array}$ \\
\hline $\begin{array}{l}\text { Chest expansion } \\
\text { Diaphragmatic excursion }\end{array}$ & $\cdots$ & $\begin{array}{r}-0.183 \\
-0.353\end{array}$ & $\begin{array}{l}-0.132 \\
-0.075\end{array}$ & $\begin{array}{l}63 \\
60\end{array}$ & $\begin{array}{l}57 \\
53\end{array}$ \\
\hline
\end{tabular}

${ }^{1}$ Symptoms recorded by standard questionnaire.

seems to increase so that for best discrimination and accuracy in grading we recommend for the present restricting measurements to bronchi in the size range 2.5 to $7.5 \mathrm{~mm}$.

\section{RELATIONSHIP WITH ANTE-MORTEM DIAGNOSIS, SYMPTOMS, AND PHYSICAL FINDINGS}

Table II gives the mean value in both ratios for each of five grades of chronic bronchitis adjudged present ante mortem, together with other relevant data including the mean $\mathrm{FEV}_{1} \%$ for each grade. Figure 7 shows the same mean ratios and their confidence limits.

Table II and Fig. 7 disclose a changing magnitude of each ratio with increasing severity of chronic bronchitis. There is, however, considerable overlap of individual subject values between grades as indicated by the magnitude of the variances shown in the table. Some of this variance may have arisen from the nature of the bronchitis classification, from inaccuracy in the ante-mortem assessments, or from accepting medical examinations conducted up to five years before death as the basis for such assessment. Some is inherent in the scientific method usedfor example, if we had restricted all wall/lumen measurements to those from the centres of the cartilaginous plates (Thurlbeck and Angus, 1964), the overlap might well have been reduced.

Looking at Fig. 7 it will be noted that the WIC/L ratio combines wide separation of grades with smaller relative variances when compared with the $G / W$ ratio. This discriminating power makes it attractive as a basis for the grading of severity of the obstructed bronchitic. In both ratios the mean values in the moderately and severely obstructed patients are significantly different by Student's t-test from those in the men who had nil or simple chronic bronchitis $(P<0.05)$.

Table III presents details of the linear correlation coefficients found between these two ratios and a number of symptoms and physical and radiological signs, including the $\mathrm{FEV}_{1}$.

This table shows, as expected, that the G/W and the WIC/L ratios correlate well with the $\mathrm{FEV}_{1}$ and the set of symptoms and signs (upper half of table) which tend to be associated with bronchitis with obstruction rather than emphysema. Of the two, the WIC/L appears to have a slight edge on the $G / W$ ratio in the determination of obstructive disease. In passing, the same set of symptoms and physical and radiological signs have been tabulated against the amount of emphysema overall (disregarding type) as graded in the post-mortem specimens, and in this instance the best correlations were obtained, as would be expected, with the signs in the lower half of the table (Table IV) and with dyspnoea and observed breathlessness rather than with wheezing.

In deriving the correlation coefficients listed in Tables III and IV we have assumed that the reaI associations would be linear in form. If, as is probable, for example, in that between quantity of 
T A B L E I V

SYMPTOMS AND PHYSICAL AND RADIOLOGICAL SIGNS WITHIN FIVE YEARS OF DEATH $v$. EMPHYSEMA GRADE (POST-MORTEM PATHOLOGY)

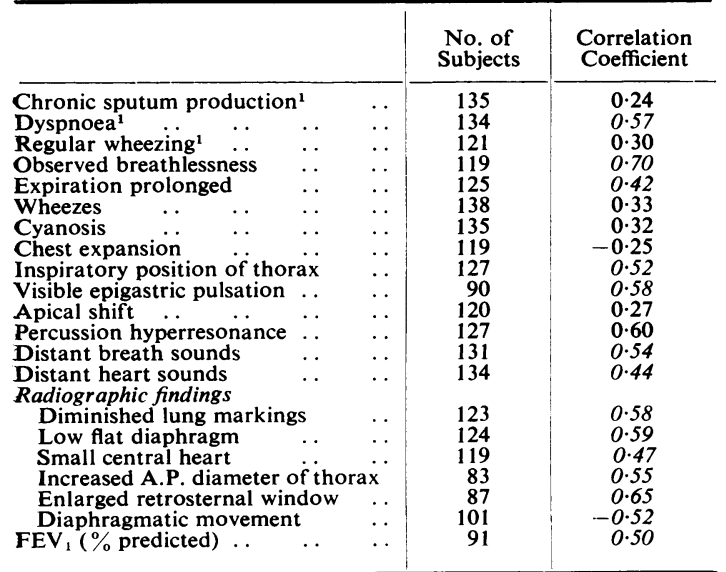

${ }^{1}$ Symptoms recorded by standard questionnaire.

emphysema and the $\mathrm{FEV}_{1}$ the association is nonlinear, our results would underestimate the true degree of correlation.

For those persons interested the details of the system of grading of individual symptoms and physical signs are available from the authors.

In Fig. 8 we have attempted to demonstrate diagrammatically the apparent relationship between the WIC/L and G/W ratios and the antemortem stages of disease as assessed by us, including some of the symptoms and signs which are likely to be present at these stages. This figure demonstrates broadly the theoretical progression of chronic bronchitis ante mortem (this commonly occurs very gradually over the age period 25 to 55 years) and expected pathology at each stage in terms of the above ratios. The figure also suggests a basis for a pathological as well as a clinical classification of severity of chronic bronchitis, both of which could be useful in epidemiological studies.

\section{DISCUSSION}

The use of ratios that normally are independent of bronchial size over a considerable range (but are altered in chronic bronchitis) was adopted by Lynne Reid $(1960,1968)$ and Thurlbeck and Angus (1964) to assess the pathology of chronic bronchitics. Compared with using actual values of the measurements this has the advantage that, within certain wide limits, precise control of bronchus size for the selection of blocks for sectioning is

\section{Nil/Simple bronchitis}

Morning sputum: $2 \mathrm{ml}$.or nil Sputum morning and during day

R.F.T.-normal range

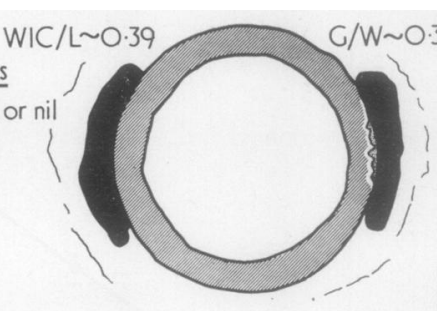

$\underline{\underline{B}}$

\section{Mild obstruction}

Sputum up to $10 \mathrm{ml}$. daily Wheeze mainly in morning Wheezes heard on forced breathing

R.F.T. towards lower limit normal approx. $60 \%-80 \%$ predicted

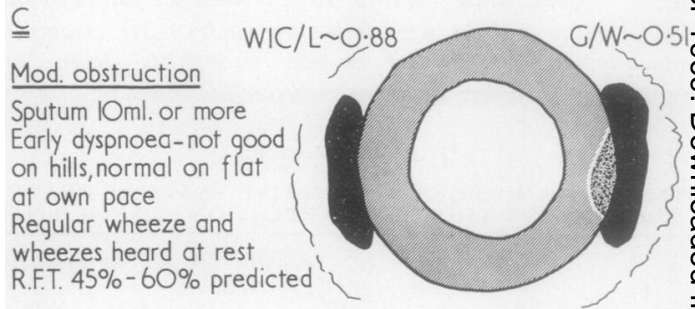

wheezes heard at rest

R.F.T. $45 \%-60 \%$ predicted
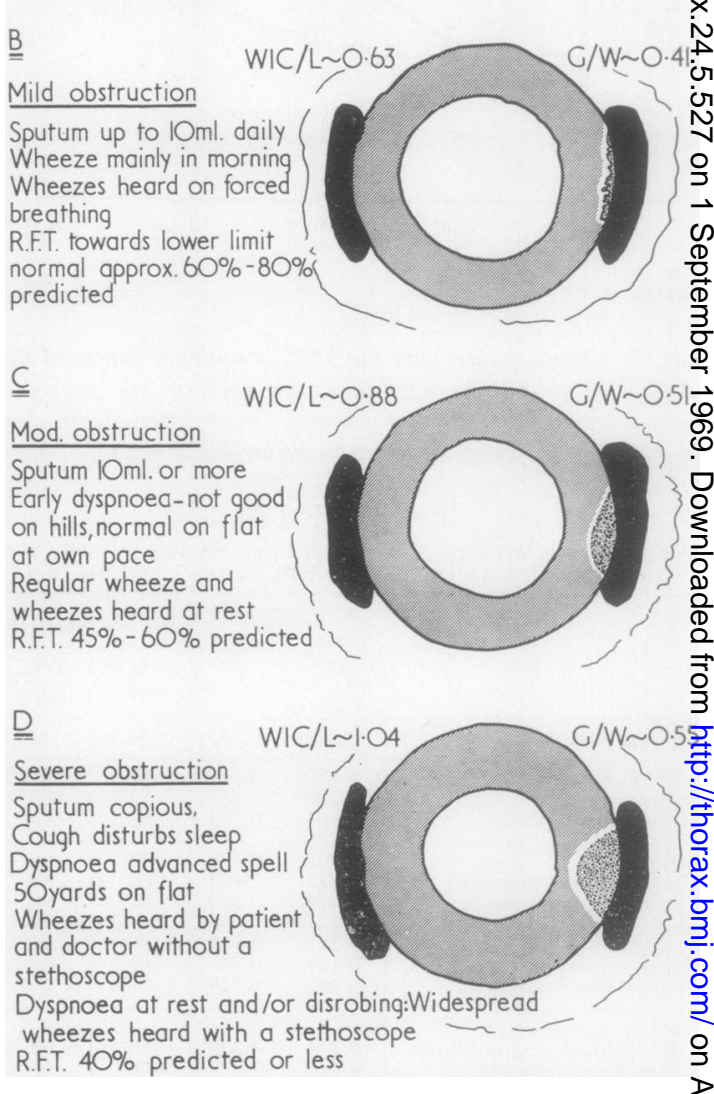

FIGS 8A, B, C, D. Diagrammatic representation of fo stages of severity of intrapulmonary obstructive bronchiot disease. Shown are selected representative ante-mortero findings together with the expected mean WIC/L and G/ $L$ L ratios as measured in post-mortem lung specimens.

not a necessary prerequisite. Of course, referenæe to cellular and other additional components $\&$ necessary for full pathological diagnosis, but ce惯 tain parameters, such as wall thickness lumen and gland size that can be quantitated, lend themselves particularly well to the study of epidemiological aspects.

Our findings with the gland/wall ratio agre closely with those of Reid and Thurlbeck an 
Angus. In this paper we have presented the results of some work with another ratio, the wall internal to cartilage/lumen radius ratio, as well as the Reid index.

It is possible by the combined use of these ratios to make a fairly good assessment of the severity of chronic bronchitis in the pathological specimen, and to adopt a system of grading of severity. It is possible to make an assessment which relates not only to the recorded amount of sputum production during life but also to the degree of airways obstruction. We are continuing to use these ratios for studying the relationships between obstructive bronchial disease and cigarette smoking and occupational groupings in our miners.

These studies have confirmed our earlier impression that chronic obstruction is not solely a clinical manifestation of emphysema and/or bronchiolar pathology. We find that the degree of narrowing of intrapulmonary bronchial airways generally is quite closely related to the amount of clinical obstruction ante mortem. Chronic bronchitis pathologically is not just hypersecretion and hypertrophy of glands, with or without cellular evidence of infection or allergy. It is also a progressive thickening of the bronchial wall inwards with consequent narrowing of airways and, after a certain threshold value of this narrowing has come about, the development of clinical airways obstruction. The thickening appears to be general -mucosal and submucosal-and not confined to the regions of the mucous glands. As to its nature, it has been suggested (Reid, 1968) that chronic hyperaemia and oedema due to hypoxia or infection may be the mechanism involved. Similarities between nasal and bronchial mucosae may be of relevance here.

This paper is published with the permission of the Joint Coal Board. We are grateful to Professor John Read, Department of Medicine, University of Sydney ; Professor Bryan Gandevia, Department of Medioine, University of New South Wales; Professor Jethro Gough, Welsh National School of Medicine, Cardiff ; Dr. Charles Fletcher, C.B.E., Royal Postgraduate Medical School, London; and Professor Lynne Reid, Institute of Diseases of the Chest, Brompton Hospital, London, for their helpful criticism and advice.

\section{REFERENCES}

Reid, Lynne (1960). Measurement of the bronchial mucous gland layer: A diagnostic yardstick in chronic bronchitis. Thorax, 15 , 132

(1968). Personal communication.

Thurlbeck, W. M., and Angus, G. E. (1964). A distribution curve for chronic bronchitis. Thorax, 19, 436. 